
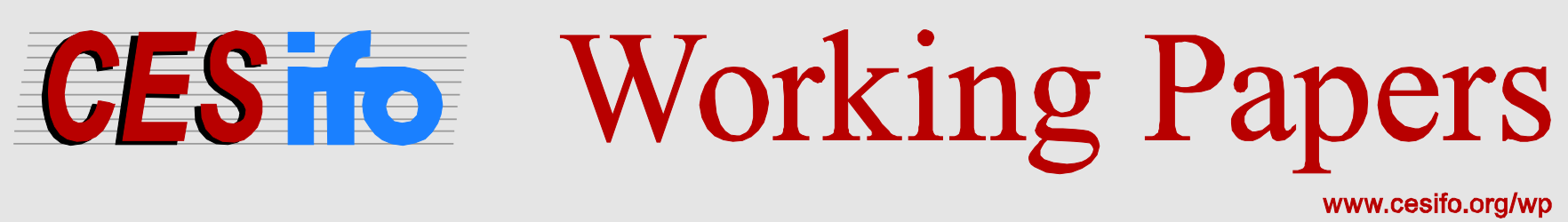

\title{
The Economics of Bitcoins - Market Characteristics and Price Jumps
}

\author{
Marc Gronwald
}

\author{
CESIFO WORKING PAPER NO. 5121 \\ CATEGORY 12: EMPIRICAL AND THEORETICAL METHODS \\ DECEMBER 2014
}

An electronic version of the paper may be downloaded

- from the SSRN website:

- from the RePEc website:

WwW.SSRN.com

- from the CESifo website:

www.RePEc.org

www.CESifo-group.org/wp

\section{CESifo}




\title{
The Economics of Bitcoins - Market Characteristics and Price Jumps
}

\begin{abstract}
This paper deals with the economics of Bitcoins in two ways. First, it broadens the discussion on how to capture Bitcoins using economic terms. Center stage in this analysis take the discussion of some unique characteristics of this market as well as the comparison of Bitcoins and gold. Second, the paper empirically analyses Bitcoin prices using an autoregressive jumpintensity GARCH model; a model tested and proven by the empirical finance community. Results suggest that Bitcoin price are particularly marked by extreme price movements; a behaviour generally observed in immature markets.
\end{abstract}

JEL-Code: C120, C220, C580, G120.

Keywords: bitcoins, jump models, commodity pricing.

\author{
Marc Gronwald \\ University of Aberdeen Business School \\ Edward Wright Building Block B \\ Dunbar Street \\ United Kingdom - Aberdeen, AB24 3QY \\ mgronwald@abdn.ac.uk
}

December 2014

The author gratefully acknowledges useful comments by Beat Hintermann. Furthermore, the author is indebted to Sandrine Ngo for motivating me to study the economics of Bitcoins. 


\section{INTRODUCTION}

This paper deals with the economics of Bitcoins. It contributes to a recently emerged literature in two ways. First, it elaborates further on how Bitcoins can be captured using economic terms. Second, the paper empirically analyses the behaviour of Bitcoin prices.

In the wake of growing general interest in Bitcoins and spectacular Bitcoin price episodes, also economists began dealing with Bitcoins. Most of the attention so far has been paid to the question whether Bitcoin is a currency or an asset, but Bitcoin prices have been studied empirically as well. The conclusion reached so far is that Bitcoins are to be considered an asset or speculative investment rather than a currency. Yermack (2013), most prominently, bases his conclusion mainly on the feature that the total number of Bitcoins is fixed. ${ }^{1}$ Lo and Wang (2014) also discuss how market characteristics hamper the ability of Bitcoins to replace fiat currencies. Glaser et al. (2014) show that new users mainly use Bitcoins as alternative investment vehicle. Luther and White (2014), however, still think that Bitcoins can become a medium of exchange. Meech and Gu (2014) discuss Bitcoin's potential to replace Gold as a "safe-haven" investment, but do come to a final conclusion. As for the empirics of Bitcoin prices, volatility observed in this market is a major concern - Yermack (2013) finds Bitcoin prices to be considerable more volatile than e.g. gold prices. Other authors study Bitcoin price drivers; issues under investigation there e.g. is predictive power of Google views (Buchholz et al., 2012; Bouoiyour and Selmi, 2014).

This paper's discussion of the economics of Bitcoins consists of two parts: first, a broadening of the analysis of some unique market characteristics, and, second, the continuation of the comparison of Bitcoins with gold. The fixed total amount of Bitcoins mentioned above is one of these market characteristics, but noteworthy is also that market fundamentals are considerably

\footnotetext{
${ }^{1}$ It falls outside the scope of this short article to extensively discuss the market features. Please consider Nakamoto's original paper on Bitcoin as peer-to-peer electronic cash system. In addition to that, Meech and $\mathrm{Gu}$ (2014), or Kristoufek (2014) also discuss this market in more detail. To the best knowledge of the author, there is currently no peer-reviewed article on the economics of Bitcoins.
} 
easier to observe than those of other markets. These market characteristics feature prominently in analyses of the potential of Bitcoins to replace other fiat currencies; this paper, however, argues that analysing these features has the potential to yield additional, deeper insights, which go beyond the "currency vs. asset" issue. The empirical behaviour of Bitcoin prices is then analysed using a econometric method tested and proven by the empirical finance community. ${ }^{2}$ The key finding is that extreme price movement play a particularly strong role; a behaviour often observed in immature markets.

The remainder of this paper is as follows: Section 2 discusses the economics of Bitcoins; Sections 3 briefly summarises existing empirical research on Bitcoins and outlines the method applied in this paper. Section 4 presents and discusses empirical results.

\section{ECONOMics of Bitcoins}

There is a fixed total number of Bitcoins of 21 million units. According to Yermack (2013, p17) this is a severe economic problem: "If Bitcoin becomes wildly successful and displaces sovereign fiat currencies, it would exert a deflationary force on the economy since the money supply would not increase in concert with economic growth." At the same time, however, this limit also implies that no "inflationary" or "deflationary" manipulation of the amount of Bitcoins is possible and that no central authority issues new money. Within the Bitcoin community this is widely considered an advantage. Lo and Wang (2014), for instance, summarise views of the Bitcoin community: "[...] national governments often impose undesirable controls, while central banks may facilitate an oversupply of currency, leading to hyperinflation" (p2). In addition to that, established payment systems are often dominated by banks (Lo and Wang, 2014). Buchholz et al. (2012) argue that investment in Bitcoins was a political statement about the role of government in finance and the economy (p2). Kroll et al. (2013), finally, point to the fact that like any fiat currency, Bitcoins have value by consensus

\footnotetext{
${ }^{2}$ To be precise, the paper analyses the Bitcoin USD exchange rate. For ease of reading, this exchange rate is referred to as Bitcoin price.
} 
and by virtue of the ability to use them to purchase goods and services (p2).

The feature of a fixed total number of Bitcoins is not the only one worth studying: As Yermack (2013, p5) points out, "all of the quantities and growth rates of Bitcoins are known with certainty by the public". Furthermore, every single trade of Bitcoins is recorded in a publicly available database (Dwyer, 2014). To put this differently, uncertainties in this market are considerably smaller compared to other markets, and there is no uncertainty regarding any political interventions. The following continuation of the comparison of Bitcoin and gold - which features prominently in the "asset vs. currency" debate - illustrates this in greater detail.

Meech and $\mathrm{Gu}$ (2014) extensively discuss analogies between Bitcoin and gold. They point out that both gold and Bitcoin are "mined" - mining is the term used to describe the process Bitcoins become available through: Bitcoins are awarded for solving certain cryptographic puzzles. This mining process is associated with cost on the one hand side and with technological change on the other - the analogies to gold mining are obvious (see Meech and $\mathrm{Gu}, 2014)$. In addition to that, both gold and Bitcoin serve as investment vehicles; Yermack (2013), among others, studies the relationship between gold prices and Bitcoin prices. The discussion of analogies can however be carried further: gold is a natural resource with a limited overall supply. Both reserves and resources, however, are uncertain; the same generally applies to the above-ground stock of gold. These uncertainties do not exist in the Bitcoin market: both the number of Bitcoins currently in circulation and the overall number is known with certainty to the public. In addition to that, it is ensured that the "production rate" of Bitcoins remains constant over time: if Bitcoin mining becomes more attractive, e.g. through higher Bitcoin prices, the complexity of the cryptographic puzzles adjusts accordingly.

In other words, market fundamentals are considerably easier to observe than in other markets and the degree of uncertainties is considerably smaller. Thus, studying this market has the potential to yield very interesting insights which go beyond the "asset vs. currency" issue. As a starting point, this paper empirically analyses Bitcoin price behaviour and briefly compares this 
behaviour to that of other commodities.

\section{EMPIRICAL ANALYSIS OF Bitcoin PRICE BEHAVIOR}

Bitcoin prices also attracted considerable attention from empirical economists. As mentioned above, Yermack (2013) studies correlations between Bitcoin prices and various currencies as well as the price of gold. Among the key findings to emerge from that paper is that Bitcoin prices are not correlated with the price of gold. Two other studies found that general public interest and/or investor attractiveness is a crucial factor. Buchholz et al. (2012), first, apply vector autoregression (VAR) models in order to study the relationships between transactions volumes, Google hits, and Bitcoin prices. Among the interesting findings is that Google hits Granger cause transaction volumes. Similar findings emerge Bouoiyour and Selmi's (2014) VAR application: they find that investor attractiveness - measured using Google views - is an important driver of Bitcoin prices. They conclude that "Bitcoin behaves heaviliy as speculative bubble" (p19). Kristoufek (2014), in contrast, finds that Bitcoin prices are not driven by speculative influences only, but that also fundamental factors such as usage in trade, money supply and price leve, play a role. Dwyer (2014), finally, compares monthly standard deviations of log returns of gold as well as Bitcoin prices and finds the latter to be considerably larger than the former.

The aim of this paper is to deepen the understanding of Bitcoin price behaviour by using a univariate time series model. It applies the so-called autoregressive jump-intensity GARCH model proposed by Chan and Maheu (2002). This model consists of a jump component which is able to capture extreme price movements, as well as a $\mathrm{GARCH}$ component which captures volatility clusters. The key difference between these price features is that volatility cluster emerge during more nervous periods, but die out again, while extreme price movements are singular events often caused by extraordinary news or other shocks to a market. Chan and Maheu's (2002) model has been tested and proven by the empirical finance community; areas of application include crude oil prices (Gronwald, 2012), exchange rates (Chan, 
2003) as well as copper (Chan and Young, 2006). The data used in this paper is from the MtGov exchange, until its shutdown the most liquid Bitcoin exchange. The period of observation is 07/02/2011 - 24/02/2014; data frequency is daily, and log-returns of the prices are used. In the following,

Figure 1: Bitcoin prices

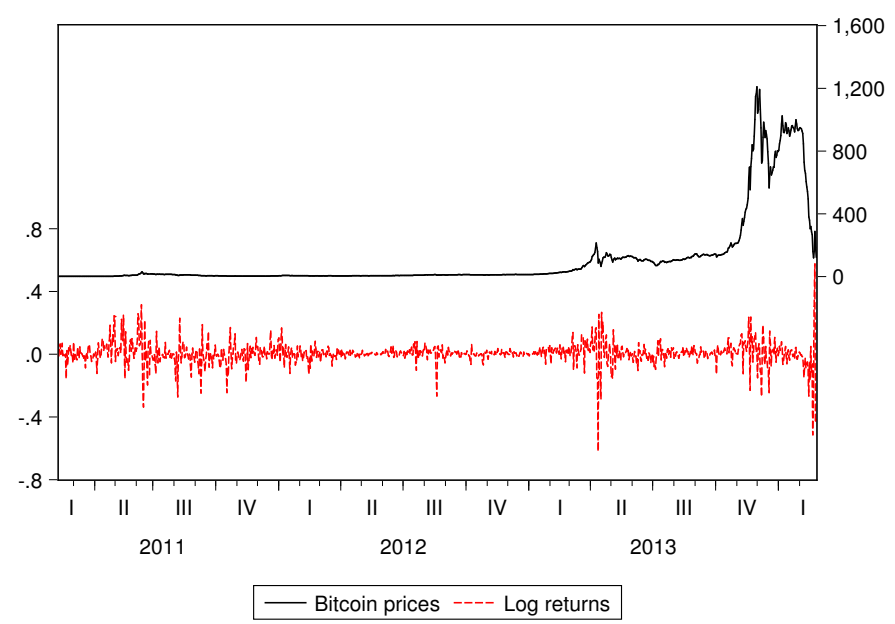

Chan and Maheu's (2002) method is outlined. ${ }^{3}$ Consider the following mean equation:

$$
y_{t}=\mu+\sum_{i=1}^{l} \phi_{i} y_{t-i}+\sqrt{h_{t}} z_{t}+\sum_{k=1}^{n_{t}} X_{t, k}
$$

with $z_{t} \sim N I D(0,1)$. It is assumed that $h_{t}$ follows a $\operatorname{GARCH}(p, q)$ process:

$$
h_{t}=\omega+\sum_{i=1}^{q} \alpha_{i} \epsilon_{t-i}^{2}+\sum_{i=1}^{p} \beta_{i} h_{t-i}
$$

The last term denotes the jump component. It is assumed that the conditional jump size $X_{t, k}$, given the history of observations $\Phi_{t-1}=\left\{y_{t-1}, \ldots, y_{1}\right\}$, is normally distributed with mean $\theta_{t}$ and variance $\delta_{t}^{2} ; n_{t}$ describes the num-

\footnotetext{
${ }^{3}$ It falls outside the scope of this short paper to extensively discuss this method. The interested reader is referred the original paper by Chan and Maheu (2002).
} 
ber of jumps that arrive between $t-1$ and $t$ and follows a Poisson distribution with $\lambda_{t}>0$ :

$$
P\left(n_{t}=j \mid \Phi_{t-i}\right)=\frac{\lambda_{t}^{j}}{j !} e^{-\lambda_{t}}
$$

$\lambda_{t}$ is called jump-intensity. The model is estimated in two variants: a constant jump-intensity model with $\lambda_{t}=\lambda, \theta_{t}=\theta$, and $\delta_{t}^{2}=\delta^{2}$ and a timevarying jump-intensity model. For the latter, $\lambda_{t}$ is assumed to follow the auto-regressive process

$$
\lambda_{t}=\lambda_{0}+\sum_{i=1}^{r} \rho_{i} \lambda_{t-i}+\sum_{i=1}^{s} \gamma_{i} \xi_{t-i} .
$$

The application of the time-varying jump intensity model, thus, allows one to study how the influence of extreme price movements changes over time. According to Nimalendran (1994), finally, the total variance $\Sigma^{2}$ of a process can be decomposed in a jump-induced part and a diffusion-induced part:

$$
\Sigma^{2}=h_{t}+\lambda_{t}\left(\theta^{2}+\delta^{2}\right)
$$

This decomposition procedure allows one to compare statistical behaviour across different markets. Finally, calculating this measure using the timevarying jump intensity makes possible to study how the share of jumpinduced variance changes over time. The following section presents and discusses the results.

\section{Results And Discussion}

Table 1 presents the estimated parameters of the constant as well as the autoregressive jump-intensity model. In each model, one lag of the endogenous variable as well as a constant are included. Table 2 compares the goodnessof-fit of the conditional jump models to that of a standard $\operatorname{GARCH}(1,1)$ model estimated as benchmark.

Figure 1 displays Bitcoin prices in levels and in growth rates; Figure 2 the estimated time-varying $\lambda$ coefficient as well as time-varying shares of 
Table 1: Constant and time-varying jump-intensity models

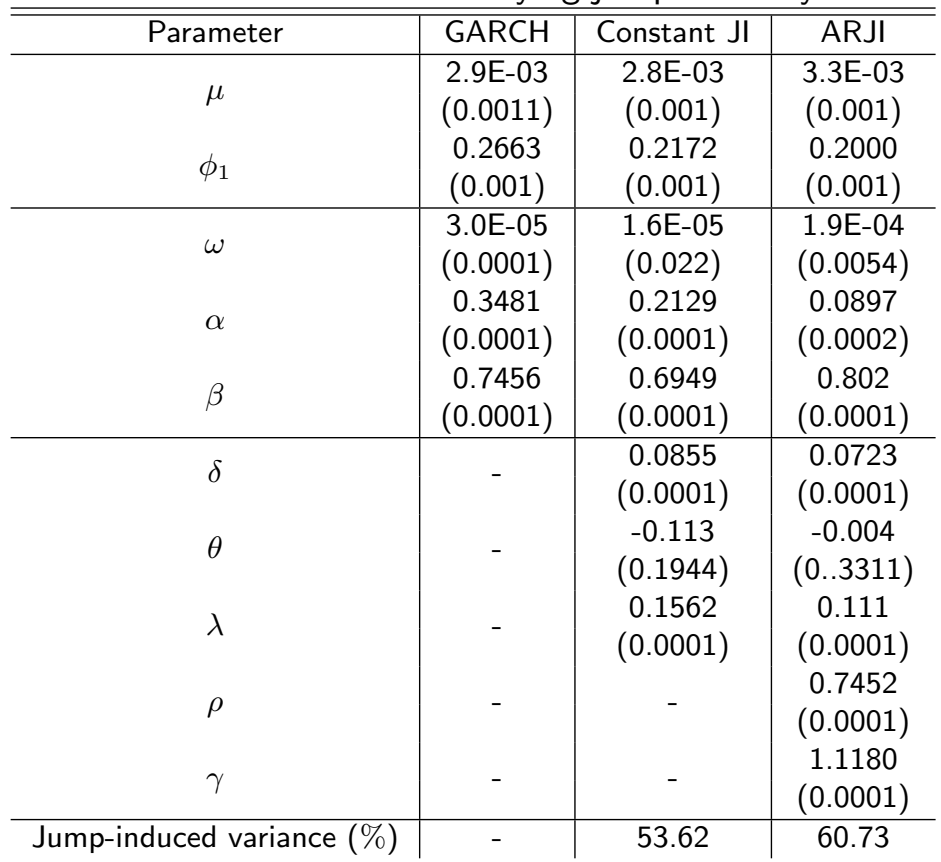

Note: p-values in parentheses.

variance induced by jumps.

The estimation results show that the model fits data reasonably well: first, all but one jump-parameter are statistically different from zero, and, moreover, a considerable share of the variance is found to be induced by jumps. Second, the jump GARCH models clearly outperform the benchmark $\operatorname{GARCH}(1,1)$. More specifically, the time-varying jump-intensity model is found to have the best goodness-of-fit. This implies that returns of Bitcoin prices are characterised by both extreme movements and conditional hetereoscedasticity. Furthermore, the influence of the extreme movements, evidenced by the good performance of the ARJI model, is varying over time.

Consulting Figure 2 shows that higher jump-intensities are more frequent in 2011 than in later years. The largest peaks however occur during the third quarter of 2012, the second quarter 2013, and beginning of 2014 . The variance decomposition, furthermore, shows that the share of variance 
Table 2: Model performance

\begin{tabular}{c|c|c|c}
\hline \hline \multicolumn{4}{c}{ Model selection criteria } \\
\hline Criterion & GARCH & Constant & ARJI \\
\hline LogL & 1874.64 & 1964.44 & 1978.42 \\
AIC & -3.359639 & -3.515621 & -3.537143 \\
BIC & -3.337110 & -3.479575 & -3.492086 \\
HQ & -3.351121 & -3.501992 & -3.520107 \\
\hline \multicolumn{3}{c}{ Likelihood ratio test } \\
\hline Models & Test statistic \\
\hline CJI vs. GARCH & $179.61^{* * *}$ & \\
ARJI vs. GARCH & & $207.56^{* * *}$ & \\
ARJI vs. CJI & & $27.95^{* * *}$ &
\end{tabular}

Note: GARCH denotes a standard $\operatorname{GARCH}(1,1)$ model, CJI the time-constant jump intensity model and ARJI the autoregressive jump intensity model.

induced by jumps fluctuates around $60 \%$. Pronounced decreases only occur three times: to the same times large peaks of the jump-intensity occur. The share of jump-induced variance drops to about $20-30 \%$. Although these findings at first glance seem to contradict each other, there is a simple explanation: in the aftermath of the extreme movements the volatility is generally higher, with a larger share of volatility captured by the GARCH component. Gronwald (2012) finds a similar pattern for the crude oil market.

Carrying forward the comparison to Gronwald (2012) yields interesting insights into Bitcoin price behaviour. Gronwald (2012) finds strong evidence of time-varying jump behaviour in crude oil prices. In particular, the share of variance induced by jumps fluctuates around $40 \%$. Although the crude oil market is generally considered to be characterised by extreme movements, this measure is considerably lower than for the Bitcoin prices. Moreover, in the aftermath of extreme price movements associated with the OPEC collapse 1986, the Gulf War 1991, and the oil price record high of 2008, this share drops drastically to just $5-10 \%$ - also much lower than the values found for the Bitcoin market. Shares of the jump-induced variance of about $60 \%$ as in the Bitcoin market are observed in the crude oil market in very early stages only - prior to 1986. In that period the crude oil market is considered very immature.

To summarise, this analysis shows that Bitcoin prices are strongly char- 
Figure 2: Jump intensities and jump-induced variance

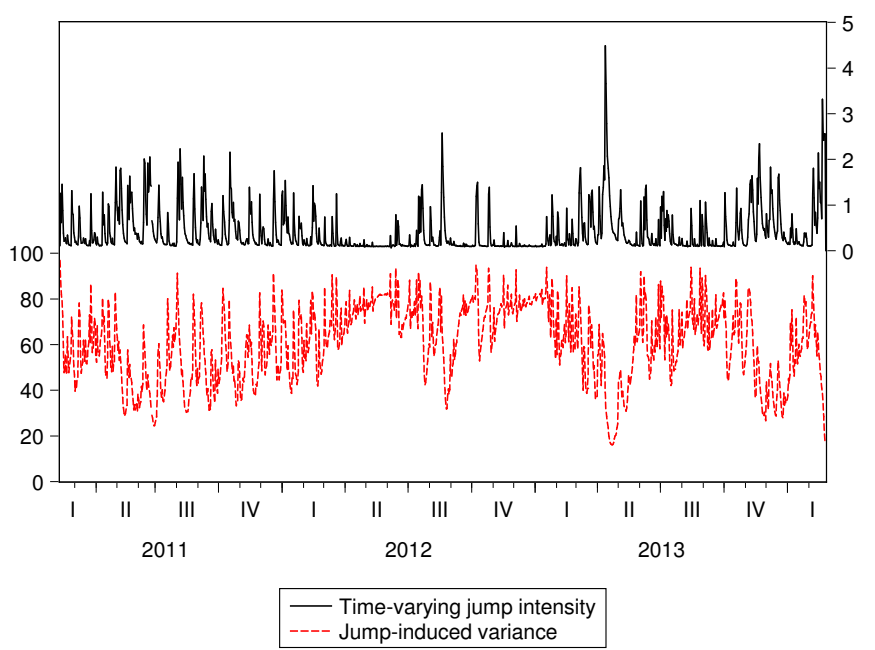

acterised by extreme price movements. As this market is still in early stages, these results are generally to be expected. In light of, first, the unique market characteristics discussed above and the resulting observability of market fundaments, and, second, the fact that attention directed to this market by investors drastically changed over time this paper yields interesting insights into price formation in maturing financial markets.

\section{REFERENCES}

Bouoiyour, J. And R.Selmi (2014). "What Bitcoin looks like?", Munich Personal Repec Archive Paper No 5809115 October 2014

Buchholz, M., J.Delaney and J. Warren (2012). "Bits and Bets: Information, Price Volatility, and Demand for Bitcoin", unpublished manuscript, available at http://www.bitcointrading.com/pdf/bitsandbets.pdf

Chan, W.H. And J.M. Maheu (2002). "Conditional Jump Dynamics in Stock Market Returns", Journal of Business Economics and Statistics 20(3): 377-389

Chan, W.H. (2003). "A correlated bivariate Poisson Jump Model for Foreign Exchange", Empirical Economics 28: 669-689 
Chan, W.H. And D. Young (2006). "Jumping Hedges: an Examination of Movements in Copper Spot and Futures Markets", Journal of Futures Markets 26: 169-188

Dwyer, G.P. (2014). "The Economics of Bitcoin and Similar Private Digital Currencies", unpublished manuscript, available at SSRN: http://ssrn.com/abstract $=2434628$ or http://dx.doi.org/10.2139/ssrn.2434628

Glaser, F., K.Zimmermann, M.Haferkorn, M.Weber and M. Siering (2014). "Bitcoin - Asset or Currency? Revealing Users' Hidden Intentions", (April 15, 2014). ECIS 2014 (Tel Aviv). Available at SSRN: http://ssrn.com/abstract=2425247

Gronwald, M. (2012). "A Characterization of Oil Price Behavior Evidence from Jump Models", Energy Economics 34,1310-1317

Kristoufek, L. (2014). "What are the Main Drivers of the Bitcoin Price? Evidence from Wavelet Coherence Analysis", unpublished manuscript, arXiv:1406.0268

Kroll, J.A., I.C..DAvey And E.W.. Felten (2013). "The Economics of Bitcoin Mining,or Bitcoin in the Presence of Adversaries", unpublished manuscript, available at http://weis2013.econinfosec.org/papers/KrollDaveyFeltenWEIS2013.pdf

Lo, S. And J.C.WAng (2014). "Bitcoin as Money?", Federal Reserve Bank of Boston Current Policy Persectives 14-4, 4 September 2014

Luther, W.J. And L.H. White (2014). "Can Bitcoin become a Major Currency?", George Mason University Department of Economics Working Paper No 14-17

Meech, J And R. Gu (2014). "Bitcoin - the "New Gold" for a "Safe-Haven" Investment", unpublished manuscript available at http://www.jmeech.mining.ubc.ca

Nakamoto, S. (No DATe). "Bitcoin: A Peer-to-Peer Electronic Cash System", unpublished manuscript, available at https://bitcoin.org/bitcoin.pdf

Nimalendran, M. (1994). "Estimating the Effects of Information Surprises and Trading on Stock Returns using a Mixed Jump-Diffusion Model", The Review of Financial Studies 7: 451-473

Yermack, M. (2013). "Is Bitcoin a Real Currency", NBER Working Paper 19747 